\title{
Relationship between Alcohol Consumption and Ocular Pressure according to Facial Flushing in Korean Men with Obesity
}

\author{
Sami Lee, Jong-Sung Kim*, Sung Soo Kim, Jin-Gyu Jung, Seok-Joon Yoon, Yuri Seo, Jihan Kim, Yoon Kyung Bae, \\ Ja Young Lee \\ Department of Family Medicine, Research Institute for Medical Science, Chungnam National University School of Medicine, Daejeon, Korea
}

\begin{abstract}
Background: This study aimed to examine the relationship between alcohol consumption and intraocular pressure (IOP) according to facial flushing in Korean men with obesity.

Methods: The study included 479 Korean men with a body mass index of $\geq 25 \mathrm{~kg} / \mathrm{m}^{2}$ (75 non-drinkers, 174 with drinking-related facial flushing, and 230 without facial flushing) who underwent health check-ups between October 1, 2016 and March 31, 2017. Multivariate logistic regression was used to assess the relationship between alcohol consumption and high IOP ( $\geq 21 \mathrm{~mm} \mathrm{Hg})$.

Results: Flushers consuming $\leq 16$ drinks per week had a significantly higher risk of high IOP than non-drinkers, depending on alcohol consumption ( $\leq 8$ standard drinks: odds ratio [OR], 4.49; 95\% confidence interval [CI], 1.05$19.25 ;>8$ but $\leq 16$ standard drinks: OR, 8.14; $95 \%$ CI, 1.37-48.45). However, when the consumption was $>16$ drinks per week, the high IOP risk did not significantly increase (OR, 0.71; 95\% CI, 0.05-10.69). In addition, there was no significant relationship between alcohol consumption and high IOP among non-flushers consuming $\leq 8$ drinks per week (OR, 2.07; 95\% CI, 0.52-8.19). However, a significantly increased risk of high IOP was observed among nonflushers consuming $>8$ drinks per week, depending on alcohol consumption ( $>8$ but $\leq 16$ standard drinks: OR, 4.84; 95\% CI, 1.14-20.61; >16 standard drinks: OR, 4.08; 95\% CI, 1.02-16.26).

Conclusion: This study suggests that obese men with alcohol flush reactions may have an increased risk of high IOP with the consumption of smaller amounts of alcohol than non-flushers.
\end{abstract}

Keywords: Alcohol Drinking; Flushing; Intraocular Pressure; Obesity

Received: August 1, 2018, Revised: February 13, 2019, Accepted: March 3, 2019

*Corresponding Author: Jong-Sung Kim https://orcid.org/0000-0001-5945-0784

Tel: +82-42-280-7548, Fax: +82-42-280-7879, E-mail: josephkim@cnu.ac.kr 


\section{INTRODUCTION}

Glaucoma is an ophthalmic disease characterized by optic nerve damage and visual field defects. ${ }^{1)}$ If not detected and treated early, $10 \%$ patients with glaucoma become blind. ${ }^{2)}$ Subjective symptoms of glaucoma do not appear until the terminal stages; hence, its early detection is difficult. ${ }^{1)}$ The causes of glaucoma are unknown, but they are presumed to be related to an abnormality of optic nerve function due to a crushed optic nerve or decreased blood flow, both of which result from increased intraocular pressure (IOP) ${ }^{3)}$ Therefore, the early diagnosis of glaucoma depends on monitoring patients for high IOP via regular examinations.

Factors that may affect IOP include age, ${ }^{4)}$ race,${ }^{5)}$ obesity, ${ }^{6)}$ hypertension, ${ }^{7)}$ diabetes mellitus, ${ }^{7)}$ alcohol consumption, ${ }^{8)}$ smoking, ${ }^{9)}$ family history of glaucoma, ${ }^{10)}$ myopia, ${ }^{5)}$ caffeine consumption, ${ }^{7)}$ exercise, ${ }^{11)}$ and abnormal thyroid function. ${ }^{12)}$ Many studies have reported that obesity is an independent risk factor for high IOP. According to these studies, obesity increases the fat tissue in the orbit, elevates episcleral venous pressure, and increases blood viscosity, thereby leading to decreased aqueous flow and outflow and increased IOP. ${ }^{13)}$ In addition, hyperlipidemia leads to changes in blood vessel sclerosis and blood osmotic pressure, which elevate episcleral venous pressure and affect IOP $^{6)}$ Sympathetic hyperfunction and hormonal changes due to obesity have also been reported to elevate IOP. ${ }^{6)}$

Numerous studies have investigated whether alcohol consumption is a risk factor for high IOP. However, no study has investigated the relationship between alcohol consumption and IOP in relation to the flushing response, which is the result of the presence of an inactive form of ALDH2 isoenzyme in the metabolization of alcohol. ${ }^{14)}$ Because the flushing response indirectly reflects alcohol metabolism, it can be used as an indicator of alcohol decomposition ability, thereby eliminating the need for genetic testing. The flushing response afflicts more than half of the East Asian popluation. ${ }^{14)}$ Therefore, studying the relationship between alcohol consumption and IOP with respect to the flushing response is necessary in Korea, a country with a particularly high drinking rate.

This study aimed to determine the relationship between alcohol consumption and IOP in Korean men with obesity and to investigate whether the risk of high IOP is affected by differences in alcohol metabolism ability, as indicated by the presence or absence of the flushing response.

\section{METHODS}

\section{Subjects}

This study was conducted on men who underwent a health examination at the Comprehensive Health Examination Center of Chungnam National University Hospital between October 1, 2016 and March 31, 2017. Among the 1,599 men who were examined, 1,545 who had records for a history of drinking, the flushing response, present illnesses, past history of diseases, and current drug use and who had undergone a tonometry test for ocular tension were considered for inclusion. From this subgroup, 479 men who had never received medical or surgical treatment for glaucoma or IOP abnormalities, had no history of medication for hypertension, were younger than 65 years, and had a body mass index (BMI) of $\geq 25 \mathrm{~kg} / \mathrm{m}^{2}$ were selected for the study. This was a retrospective cross-sectional research approved by the institutional review board of Chungnam National University Hospital (IRB approval no., 2017-10-035) and the requirement for informed consent was waived. It conformed to the ethics guidelines of the Declaration of Helsinki.

\section{Study Method}

Information on past and current medical history, drug use history, and smoking and drinking habits was collected through a questionnaire that the subjects answered before the examination. Data from the comprehensive health examination were used for key physical measurements such as height, weight, BMI, blood pressure, and IOP.

Height was measured to one decimal place $(0.1 \mathrm{~cm})$ by using an automatic height measurement device. Weight was measured to two decimal places $(0.01 \mathrm{~kg})$ while the subject was wearing an examination uniform and after he had been fasting for at least 12 hours. BMI (in kg/ $\mathrm{m}^{2}$ ) was automatically calculated from the subject's weight and height. According to the standard for the Asian and Pacific regions published by the World Health Organization, a BMI of $\geq 25 \mathrm{~kg} / \mathrm{m}^{2}$ indicates obesity. The waistline of the subjects was measured to one decimal place $(0.1 \mathrm{~cm})$ at the midpoint between the 12th rib and the upper iliac crest after the subject had exhaled.

Drinking behavior was measured as average alcohol consumption per week, which was calculated by multiplying the average amount of alcohol consumed at each drinking session over the previous year by the number of drinking sessions per week. The average alcohol consumption per drinking session was calculated by converting $14 \mathrm{~g}$ of alcohol into 1 standard drink in accordance with the National Institute

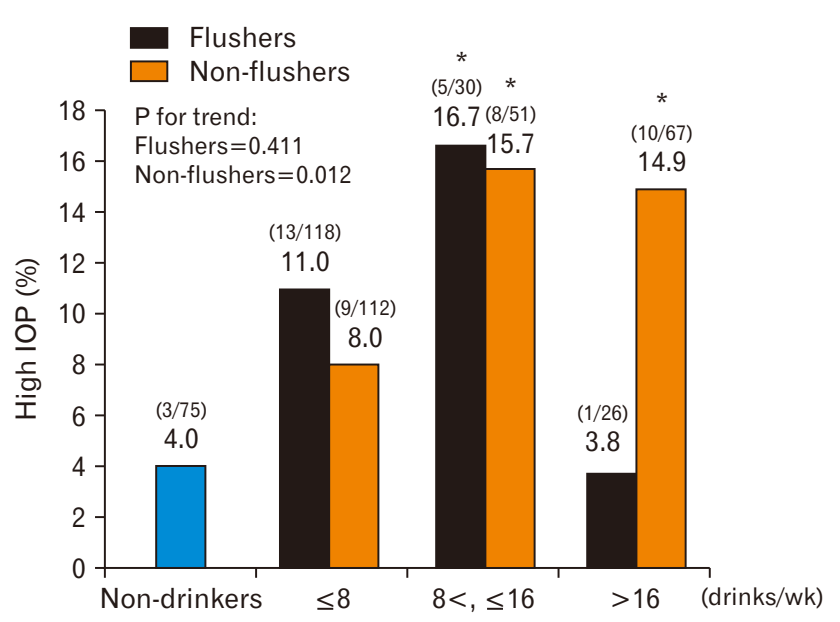

Figure 1. Prevalence of high IOP in subjects with body mass index $\geq 25 \mathrm{~kg} / \mathrm{m}^{2}$ according to weekly drinks. IOP, intraocular pressure. ${ }^{*} \mathrm{P}<0.05$ compared to nondrinkers according to the chi-square test. 
on Alcohol Abuse and Alcoholism guidelines. ${ }^{15)}$ This equated to 1.5 ounces of foreign liquor at $40 \%$ alcohol $(\fallingdotseq 45 \mathrm{~mL}), 5$ ounces of wine $(\fallingdotseq 150 \mathrm{~mL})$, and 12 ounces of beer $(355 \mathrm{~mL})$. Thus, 1 standard drink corresponded to one glass of foreign liquor or wine or one can or bottle of beer. For draft beer, $500 \mathrm{~mL}$ corresponded to 1.3 standard drinks. In addition, one cup of makgeolli (about $300 \mathrm{~mL}$ ) corresponded to 1 standard drink, and one bottle of makgeolli $(750 \mathrm{~mL})$ corresponded to 2.5 standard drinks. Moreover, one standard drink of $20 \%$ soju corresponded to $1 / 4$ of soju bottle (about $90 \mathrm{~mL}$ ). One drink of a standard soju cup corresponded to a standard 4/7 cup, and when converted into a standard drink, it was calculated up to one decimal place.

The flushing response was measured using a survey item that categorized responses into "always," "sometimes," and "never," in accordance with method used by Yokoyama et al. ${ }^{16)}$ The subjects who drank alcohol who answered "always" and "sometimes" were categorized as flushers and those who answered "never" were categorized as nonflushers. This categorization was based on the high sensitivity and specificity for screening the inactive ALDH2 genotype (96.1\% and $79.0 \%$, respectively). ${ }^{16)}$
On the basis of the questionnaire, the current smoking status was classified into current, past, or lifetime non-smokers. According to the International Physical Activity Questionnaire, ${ }^{17)}$ subjects who engaged in intense physical activity at least 3 times a week for $\geq 20$ minutes or those who performed moderate physical activity at least 5 times a week for $\geq 30$ minutes were placed in the regular exercise group. Subjects who did not exercise at all were placed in the non-exercise group, while those who exercised but did not meet the criteria for the regular exercise group were placed in the irregular exercise group.

IOP was measured in both eyes without topical anesthesia using a non-contact tonometer (PC-80; Topcon Corp., Tokyo, Japan). High IOP was defined as an IOP of $21 \mathrm{~mm}$ Hg or higher in either eye.

\section{Statistical Analysis}

The subjects were divided into one non-drinking and three drinking groups ( $\leq 8$ standard drinks, $>8$ drinks but $\leq 16$ drinks, and $>16$ drinks per week). On the basis of the non-drinking status, the general characteristics, physical measurements, and tonometry results were analyzed between flushers and non-flushers. Chi-square tests were used to ana-

Table 1. Characteristics of subjects

\begin{tabular}{|c|c|c|c|}
\hline \multirow{2}{*}{ Characteristic } & \multirow{2}{*}{ Non-drinkers $(n=75)$} & \multicolumn{2}{|c|}{ Drinkers $(n=404)$} \\
\hline & & Flushers $(n=174)$ & Non-flushers $(n=230)$ \\
\hline Age (y) & $49.7 \pm 9.2$ & $47.1 \pm 9.3$ & $44.8 \pm 9.2^{\star \star \star}$ \\
\hline Weight (kg) & $79.8 \pm 10.1$ & $81.2 \pm 9.6$ & $81.8 \pm 9.6$ \\
\hline Height $(\mathrm{cm})$ & $170.5 \pm 5.9$ & $172.3 \pm 6.0$ & $172.6 \pm 6.1^{*}$ \\
\hline Body mass index (kg/m²) & $27.4 \pm 2.5$ & $27.3 \pm 2.4$ & $27.4 \pm 2.5$ \\
\hline Waist circumference $(\mathrm{cm})$ & $94.2 \pm 6.9$ & $93.9 \pm 6.5$ & $93.7 \pm 6.8$ \\
\hline Systolic blood pressure (mm Hg) & $127.4 \pm 12.2$ & $131.0 \pm 12.4$ & $130.3 \pm 12.3$ \\
\hline Diastolic blood pressure (mm Hg) & $80.0 \pm 9.2$ & $82.9 \pm 9.5$ & $82.5 \pm 10.2$ \\
\hline Aspartate aminotransferase (IU/L) & $25.9 \pm 11.3$ & $28.4 \pm 16.2$ & $29.5 \pm 17.0$ \\
\hline Alanine aminotransferase (IU/L) & $35.4 \pm 22.8$ & $37.7 \pm 30.2$ & $37.5 \pm 29.6$ \\
\hline Gamma-glutamyltransferase (IU/L) & $37.5 \pm 21.6$ & $53.9 \pm 53.9^{*}$ & $59.5 \pm 46.4^{\star \star}$ \\
\hline Low-density lipoprotein cholesterol (mg/dL) & $135.2 \pm 28.8$ & $132.6 \pm 30.6$ & $126.9 \pm 27.4$ \\
\hline High-density lipoprotein cholesterol (mg/dL) & $44.8 \pm 9.0$ & $47.7 \pm 10.9$ & $49.3 \pm 11.2^{\star \star}$ \\
\hline Triglyceride $(\mathrm{mg} / \mathrm{dL})$ & $166.9 \pm 105.8$ & $188.5 \pm 122.1$ & $191.1 \pm 113.6$ \\
\hline Total cholesterol (mg/dL) & $206.6 \pm 32.6$ & $208.7 \pm 33.7$ & $204.8 \pm 31.7$ \\
\hline Glucose (mg/dL) & $100.4 \pm 15.8$ & $103.4 \pm 18.3$ & $105.4 \pm 26.9$ \\
\hline Left IOP (mm Hg) & $14.3 \pm 3.7$ & $15.2 \pm 3.4$ & $15.4 \pm 3.5$ \\
\hline Right IOP (mm Hg) & $13.9 \pm 3.3$ & $14.6 \pm 3.7$ & $14.8 \pm 3.4$ \\
\hline \multicolumn{4}{|l|}{ High IOP } \\
\hline No & 72 (96.0) & $155(89.1)$ & 203 (88.3) \\
\hline Yes & $3(4.0)$ & $19(10.9)$ & $27(11.7)$ \\
\hline \multicolumn{4}{|l|}{ Smoking } \\
\hline Non-smoker & $27(36.0)$ & $41(23.9)^{\star}$ & $55(23.9)^{\star}$ \\
\hline Ex-smoker & $24(32.0)$ & $73(29.6)^{*}$ & $68(29.6)^{*}$ \\
\hline Current-smoker & $24(32.0)$ & $60(46.5)^{\star}$ & $107(46.5)^{*}$ \\
\hline \multicolumn{4}{|l|}{ Exercise } \\
\hline None & 31 (41.3) & $53(30.5)$ & $59(25.7)$ \\
\hline Irregular & 19 (25.3) & 54 (31.0) & $83(36.1)$ \\
\hline Regular & 25 (33.3) & $67(38.5)$ & $88(38.3)$ \\
\hline $\operatorname{Drinks}^{\dagger}$ (/wk) & & $8.4 \pm 10.0^{* * *}$ & $12.7 \pm 10.3^{\star \star \star}$ \\
\hline
\end{tabular}

Values are presented as mean \pm standard deviation or number (\%).

IOP, intraocular pressure.

${ }^{*} \mathrm{P}<0.05,{ }^{* \star} \mathrm{P}<0.01,{ }^{* \star *} \mathrm{P}<0.001$ compared to non-drinkers by analysis of variance with Scheffe post-hoc test or chi-square test. ${ }^{\dagger}$ One standard drink=alcohol $14 \mathrm{~g}$. 
lyze the prevalence of high IOP in obese subjects according to weekly drinks and $P$ for trend, as shown in Figure 1. Chi-square tests were also used for categorical variables, such as smoking and exercise, as shown in Table 1, and one-way analysis of variance (ANOVA) was used for continuous variables, such as age, height, weight, BMI, and waistline. A Scheffe test was used as a post-hoc test for ANOVA. Logistic regression analysis was also conducted to evaluate the risk of high IOP in flushers and non-flushers. Model 1 was not adjusted for confounding variables, while model 2 was adjusted for BMI and systolic blood pressure (SBP), which are known to increase IOP. Model 3 was also adjusted for factors known to elevate IOP, such as age, smoking, and any history of diabetes, abnormal thyroid function, cardiovascular diseases, total cholesterol, cataract surgery, refractory surgery (laser-assisted in situ keratomileusis [LASIK] or laser-assisted subepithelial keratectomy [LASEK]), and strabismus surgery. Statistical analyses were conducted using PASW Statistics for Windows/Macintosh ver. 18.0 (SPSS Inc., Chicago, IL, USA) with a statistical significance of $\mathrm{P}<0.05$.

\section{RESULTS}

\section{Characteristics of the Study Subjects}

Among the 479 subjects, 75 were non-drinkers and 404 were drinkers. In the latter group, 174 were flushers and 230 were non-flushers (Table 1). The average age ( \pm standard deviation) of non-flushers (44.8 \pm 9.2$)$ was significantly lower than that of non-drinkers $(49.7 \pm 9.2, \mathrm{P}<0.001)$;

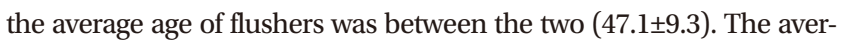
age height of non-flushers was significantly higher than that of nondrinkers $(\mathrm{P}<0.05)$, while the proportion of smokers was significantly higher in both drinking groups $(\mathrm{P}<0.05)$. Although not statistically significant, the average IOP for both eyes was higher in drinkers than in non-drinkers, with average IOPs of $15.2 \pm 3.4 \mathrm{~mm} \mathrm{Hg}$ in flushers $(\mathrm{P}=0.195)$ and $15.4 \pm 3.5 \mathrm{~mm} \mathrm{Hg}$ in non-flushers $(\mathrm{P}=0.059)$ for the left eyes, and 14.6 $\pm 3.7 \mathrm{~mm} \mathrm{Hg}$ in flushers $(\mathrm{P}=0.343)$ and $14.8 \pm 3.4 \mathrm{~mm} \mathrm{Hg}$ in non-flushers $(\mathrm{P}=0.136)$ for the right eyes. The proportion of high IOP in drinkers was higher than that in non-drinkers, even though the difference was not statistically significant $(4 \%, 10.9 \%$, and $11.7 \%$ in non-drinkers, flushers, and non-flushers, respectively; $\mathrm{P}=0.147$ ). Weight, BMI, waist circumference, SBP, diastolic blood pressure, and

Table 2. Odds ratio of high intraocular pressure in flushers and non-flushers compared with non-drinkers

\begin{tabular}{lcccc}
\hline & \multicolumn{4}{c}{ Drinkers } \\
\cline { 2 - 5 } & Flushers & P-value & Non-flushers & P-value \\
\hline Non-drinkers & 1 & & 1 & \\
Model 1 & $2.94(0.84-10.26)$ & 0.090 & $3.19(0.94-10.84)$ & 0.063 \\
Model 2 & $2.97(0.85-10.41)$ & 0.089 & $3.21(0.94-10.91)$ & 0.062 \\
Model 3 & $3.51(0.95-12.98)$ & 0.060 & $3.53(0.97-12.77)$ & 0.055 \\
\hline
\end{tabular}

Values are presented as odds ratio ( $95 \%$ confidence interval). Model 1: crude; model 2: adjusted for BMI and SBP; model 3: adjusted for BMI, SBP, age, smoking, diabetes mellitus, total cholesterol, cardiovascular diseases, abnormal thyroid function, and eye operations.

BMI, body mass index; SBP, systolic blood pressure. aspartate aminotransferase, alanine aminotransferase, low-density lipoprotein cholesterol, triglyceride, total cholesterol, and blood glucose levels were not significantly different in flushers and non-flushers than they were in non-drinkers (Table 1).

\section{Relationship between Alcohol Consumption and Intraocular Pressure according to the Flushing Response}

Figure 1 presents the results of the chi-square tests comparing the proportion of subjects with high IOP between non-drinkers and drinkers, who were further subdivided into three groups ( $\leq 8$ standard drinks, $>8$ but $\leq 16$ drinks, and $>16$ drinks a week). Among men with a BMI of $\geq 25$ $\mathrm{kg} / \mathrm{m}^{2}$, the proportion with high IOP among flushers was higher than that among non-drinkers, except for those who consumed $>16$ drinks per week. In particular, the proportion of subjects with high IOP was significantly higher in the $>8$ but $\leq 16$ drink group than in the nondrinking group $(\mathrm{P}=0.041)$. Among non-flushers, the prevalence of high IOP was higher than that among non-drinkers, especially with significance values of $\mathrm{P}=0.049$ for the $>8$ but $\leq 16$ drink group and $\mathrm{P}=0.024$ for the $>16$ drink group. A trend towards an increased prevalence of high IOP with greater amount of weekly drinks was observed in non-flushers ( $\mathrm{P}$ for trend $=0.012$ ), but not in flushers ( $\mathrm{P}$ for trend=0.411).

\section{Logistic Regression Analysis of the Relationship between Alcohol Consumption and High Intraocular Pressure according to Facial Flushing}

The results of logistic regression analysis are shown in Tables 2 and 3. In both tables, model 1 reflects the crude data, model 2 includes data adjusted for BMI and SBP, and model 3 includes data adjusted for age, smoking status, diabetes, total cholesterol, cardiovascular disease, abnormal thyroid function, cataract, and a history of refractory surgery

Table 3. Relationship between high intraocular pressure and weekly alcohol drinks in accordance to facial flushing

\begin{tabular}{ccccc}
\hline & \multicolumn{4}{c}{ Drinkers } \\
\cline { 2 - 5 } & Flushers & P-value & Non-flushers & P-value \\
\hline Non-drinkers & 1 & & 1 & \\
$\leq 8$ drinks & & & & \\
$\quad$ Model 1 & $2.97(0.82-10.80)$ & 0.098 & $2.10(0.55-8.02)$ & 0.279 \\
Model 2 & $3.03(0.83-11.10)$ & 0.094 & $2.15(0.56-8.23)$ & 0.265 \\
Model 3 & $4.49(1.05-19.25)$ & 0.043 & $2.07(0.52-8.19)$ & 0.300 \\
$8<, \leq 16$ drinks & & & & \\
Model 1 & $4.80(1.07-21.55)$ & 0.041 & $4.47(1.12-17.74)$ & 0.034 \\
Model 2 & $4.77(1.00-22.79)$ & 0.050 & $4.64(1.16-18.56)$ & 0.030 \\
Model 3 & $8.14(1.37-48.45)$ & 0.021 & $4.84(1.14-20.61)$ & 0.033 \\
$>16$ drinks & & & & \\
Model 1 & $0.96(0.10-9.66)$ & 0.972 & $4.21(1.11-16.02)$ & 0.035 \\
Model 2 & $0.99(0.10-10.07)$ & 0.992 & $4.40(1.15-16.88)$ & 0.031 \\
Model 3 & $0.71(0.05-10.69)$ & 0.807 & $4.08(1.02-16.26)$ & 0.047 \\
\hline
\end{tabular}

Values are presented as odds ratio ( $95 \%$ confidence interval). Model 1: crude; model 2: adjusted for BMl and SBP; model 3: adjusted for BMI, SBP, age, smoking, diabetes mellitus, total cholesterol, cardiovascular diseases, abnormal thyroid function, and eye operations.

BMI, body mass index; SBP, systolic blood pressure. 
(including LASIK or LASEK) and strabismus surgery.

Table 2 shows the multivariate-adjusted odds ratio (OR) of high IOP among flushers and non-flushers compared to those among nondrinkers, irrespective of weekly alcohol amount. All the models showed that the results were not statistically significant among the groups.

Table 3 summarizes the results of the logistic regression to analyze the relationship between weekly alcohol consumption and IOP in accordance with ALDH2 activity. In model 1, flushers exhibited a higher risk of high IOP than non-drinkers only when alcohol consumption per week was 8-16 drinks (OR, 4.80; confidence interval [CI], 1.0721.55; $\mathrm{P}=0.041$ ). For an alcohol consumption of $\leq 8$ drinks or $>16$ drinks, the risk of high IOP did not significantly increase (OR, 2.97; 95\% CI, 0.82-10.80; $\mathrm{P}=0.098$ and $\mathrm{OR}, 0.96$; 95\% CI, 0.10-9.66; $\mathrm{P}=0.972$, respectively). However, non-flushers did not demonstrate any significant increase in the risk of high IOP when alcohol consumption per week was $\leq 8$ drinks (OR, 2.10; 95\% CI, 0.55-8.02; $\mathrm{P}=0.279$ ). In contrast, for the 8-16 drink group (OR, 4.47; 95\% CI, 1.12-17.74; $\mathrm{P}=0.034$ ) and the $>16$ drink group (OR, 4.21; 95\% CI, 1.11-16.02; $\mathrm{P}=0.035$ ), the risk of high IOP increased significantly.

In contrast to model 1 , model 2 , which incorporated data adjusted for BMI and SBP as factors that affected IOP, found no significant increase in the risk of high IOP among flushers in the 8-16 drink group (OR, 4.77; 95\% CI, 1.00-22.79; $\mathrm{P}=0.050$ ). The risk of high IOP significantly increased in the 8-16 drink group (OR, 4.64; 95\% CI, 1.16-18.56; $\mathrm{P}=0.030$ ) and the $>16$ drink group (OR, 4.40; 95\% CI, 1.15-16.88; $\mathrm{P}=0.031$ ) of drinkers who did not experience the flushing response.

In model 3, all factors known to affect IOP were corrected. Therefore, the ORs for high IOP among flushers significantly increased in the $\leq 8$ drink group (OR, 4.49; 95\% CI, 1.05-19.25; $\mathrm{P}=0.043$ ) and the 8-16 drink group (OR, 8.14; 95\% CI, 1.37-48.45; $\mathrm{P}=0.021$ ). The equivalent ORs among non-flushers also significantly increased in the 8-16 drink group (OR, 4.84; 95\% CI, 1.14-20.61; $\mathrm{P}=0.033$ ) and the $>16$ drink group (OR, 4.08; 95\% CI, 1.02-16.26; $\mathrm{P}=0.047$ ).

\section{DISCUSSION}

In this study, we aimed to investigate the effect of alcohol consumption on the risk of high IOP in Korean men with obesity and to identify whether this relationship was affected by the presence of the flushing response. The risk of high IOP increased by 4.49-8.14 times in flushers than in non-drinkers when alcohol consumption was $\leq 16$ drinks a week. Moreover, the risk of high IOP increased by 4.08-4.84 times in non-flushers than in non-drinkers when alcohol consumption exceeded 8 drinks a week.

The results of the current study are consistent with those of previous studies, which found that alcohol consumption and IOP had a positive correlation. The Barbados Eye Study conducted in the United States found a significant increase in the risk of high IOP in men who had consumed alcohol in the previous year $(\mathrm{P}<0.01) .{ }^{18)}$ According to a study in Japan, the average IOP in men increased as alcohol consump- tion increased (P for trend $<0.001$ ). ${ }^{19)}$ The reason for the higher risk of high IOP with alcohol consumption remains unclarified, but drinking suppresses the secretion of antidiuretic hormone (ADH) and causes dehydration by increasing urine production. As a result, blood viscosity and flow resistance increase, thus potentially increasing IOP. ${ }^{20)}$ In addition, chronic alcohol consumption increases the release of cortisol (a stress hormone), leading to elevated blood pressure, ${ }^{21)}$ which may be a cause of the high IOP. In contrast, Peczon and Grant ${ }^{22)}$ found that when drinking $50 \mathrm{~mL}$ of whiskey or $1 \mathrm{~L}$ of beer, IOP drops by 1-6 $\mathrm{mm} \mathrm{Hg}$ in individuals with normal eyes and by $30 \mathrm{~mm} \mathrm{Hg}$ in those with open-angle glaucoma. Notably, this effect occurred only 1-3 hours after drinking; therefore, the results of their study may not be applicable to chronic effects. ${ }^{23)}$

Our study also found that the risk of high IOP started increasing even with a smaller amount of alcohol in flushers than in non-flushers. This mechanism requires further study, but it is hypothesized that the increase in urine production due to the suppression of $\mathrm{ADH}$ secretion while drinking alcohol leads to dehydration and an increase in blood viscosity and flow resistance, thus increasing IOP. In particular, the inactivation of the $A L D H 2$ gene leads to a greater reaction to drinking in flushers than in non-flushers, possibly increasing IOP further. ${ }^{24)} \mathrm{In}$ addition, some studies have shown that the risk of hypertension can be 2 times higher in flushers than in non-flushers when compared to the risk in non-drinkers, even when flushers consume half the amount of alcohol than non-flushers. This is because flushers genetically have difficulty in decomposing acetaldehyde. ${ }^{25)}$ Therefore, the risk of high IOP and hypertension is assumed to increase. ${ }^{26)}$

In the present study, the risk of high IOP in flushers was significantly increased by drinking $\leq 16$ drinks a week. However, the increase in the risk of high IOP was not significant for flushers who had $>16$ drinks a week. Alcohol consumption is generally lower among flushers than among non-flushers, and few flushers are heavy drinkers. ${ }^{27)}$ The proportion of flushers was as low as $3.8 \%$, and among them, only one drinker had a high IOP; therefore, the results may not be statistically significant. Hence, further research including a greater number of heavy drinkers with the flushing response is required to confirm these results.

This study had some limitations. First, it was a cross-sectional study, and hence, it cannot confirm or explain a causal relationship between alcohol consumption and IOP in the presence of obesity and/or the flushing response. Second, this study was conducted using data from subjects at a single examination center in a university hospital, and hence, the results may not be generalizable to all obese men. Third, this study was limited to men because of the small number of female drinkers. Although our study excluded patients with glaucoma and users of medication related to IOP, a possibility of not having completely excluded patients with glaucoma and a normal IOP still exists.

These limitations notwithstanding, this study, to our knowledge, is the first to analyze the relationship between alcohol consumption and IOP according to the presence or absence of the flushing response. This study is also significant in that it used weekly alcohol consump- 
tion as a drinking behavior and investigated its effect upon IOP while adjusting for many variables known to affect it. However, our result does not show clearly whether facial flushing affects high IOP independent of alcohol intake. Thus, further study will be needed to analyze the interaction between alcohol consumption and facial flushing in response to high IOP. Moreover, our study has only focused on the obese population as obesity has been suggested as an important independent risk factor that increases IOP. Although our study found that obese men with the flushing response may have a higher risk of increased IOP with a smaller amount of alcohol than those without the flushing response, further study is required to investigate whether this finding applies to the non-obese population as well.

IOP is the only controllable risk in patients with glaucoma, regardless of the presence of high IOP. ${ }^{28)}$ Therefore, IOP is the most important factor in the occurrence of glaucoma; this increases the significance of the current study. Most health examinations include IOP tests as part of a basic ophthalmologic examination, ${ }^{29)}$ and hence, if a comprehensive visual examination including a visual field test is impossible, the measurement of IOP can be used to evaluate the possibility of glaucoma.

In conclusion, the risk of high IOP in non-flushers does not increase with alcohol consumption of $\leq 8$ standard drinks a week, but the risk of high IOP increases even with much lower alcohol consumption in flushers. These results are consistent with the Korean alcohol guidelines for optimal drinking, which recommend that alcohol consumption limit for individuals who have flushing response should be half of that for individuals who do not have flushing response because the harmful effects of alcohol are greater in the former group. ${ }^{30)}$ Therefore, it is recommended that obese men who have the flushing response do not drink and that even non-flushers moderate their alcohol consumption.

\section{CONFLICT OF INTEREST}

No potential conflict of interest relevant to this article was reported.

\section{ORCID}

Sami Lee: https://orcid.org/0000-0003-3653-7734

Jong-Sung Kim: https://orcid.org/0000-0001-5945-0784

Sung Soo Kim: https://orcid.org/0000-0001-9417-7728

Jin-Gyu Jung: https://orcid.org/0000-0003-1400-4187

Seok-Joon Yoon: https://orcid.org/0000-0002-5238-7724

Yuri Seo: https://orcid.org/0000-0001-6371-4025

Jihan Kim: https://orcid.org/0000-0003-1364-5169

Yoon Kyung Bae: https://orcid.org/0000-0003-4683-9779

Ja Young Lee: https://orcid.org/0000-0002-3959-8949

\section{REFERENCES}

1. Weinreb RN, Aung T, Medeiros FA. The pathophysiology and treat- ment of glaucoma: a review. JAMA 2014;311:1901-11.

2. Quigley HA, Broman AT. The number of people with glaucoma worldwide in 2010 and 2020. Br J Ophthalmol 2006;90:262-7.

3. Coleman AL. Glaucoma. Lancet 1999;354:1803-10.

4. Shiose Y. The aging effect on intraocular pressure in an apparently normal population. Arch Ophthalmol 1984;102:883-7.

5. Weih LM, Mukesh BN, McCarty CA, Taylor HR. Association of demographic, familial, medical, and ocular factors with intraocular pressure. Arch Ophthalmol 2001;119:875-80.

6. Mori K, Ando F, Nomura H, Sato Y, Shimokata H. Relationship between intraocular pressure and obesity in Japan. Int J Epidemiol 2000; 29:661-6.

7. Rochtchina E, Mitchell P, Wang JJ. Relationship between age and intraocular pressure: the Blue Mountains Eye Study. Clin Exp Ophthalmol 2002;30:173-5.

8. Lin HY, Hsu WM, Chou P, Liu CJ, Chou JC, Tsai SY, et al. Intraocular pressure measured with a noncontact tonometer in an elderly Chinese population: the Shihpai Eye Study. Arch Ophthalmol 2005;123: 381-6.

9. Lee AJ, Rochtchina E, Wang JJ, Healey PR, Mitchell P. Does smoking affect intraocular pressure?: findings from the Blue Mountains Eye Study. J Glaucoma 2003;12:209-12.

10. Tielsch JM, Katz J, Sommer A, Quigley HA, Javitt JC. Family history and risk of primary open angle glaucoma: the Baltimore Eye Survey. Arch Ophthalmol 1994;112:69-73.

11. Lempert P, Cooper KH, Culver JF, Tredici TJ. The effect of exercise on intraocular pressure. Am J Ophthalmol 1967;63:1673-6.

12. Centanni M, Cesareo R, Verallo O, Brinelli M, Canettieri G, Viceconti $\mathrm{N}$, et al. Reversible increase of intraocular pressure in subclinical hypothyroid patients. Eur J Endocrinol 1997;136:595-8.

13. Dielemans I, Vingerling JR, Algra D, Hofman A, Grobbee DE, de Jong PT. Primary open-angle glaucoma, intraocular pressure, and systemic blood pressure in the general elderly population: the Rotterdam Study. Ophthalmology 1995;102:54-60.

14. Agarwal DP, Harada S, Goedde HW. Racial differences in biological sensitivity to ethanol: the role of alcohol dehydrogenase and aldehyde dehydrogenase isozymes. Alcohol Clin Exp Res 1981;5:12-6.

15. National Institute on Alcohol Abuse and Alcoholism. Helping patients who drink too much: a clinician's guide: updated 2005 edition [Internet]. Bethesda (MD): NIH Publication; 2007 [cited 2017 Dec 13]. Available from: http://pubs.niaaa.nih.gov/publications/Practitioner/ CliniciansGuide2005/guide.pdf.

16. Yokoyama A, Muramatsu T, Ohmori T, Kumagai Y, Higuchi S, Ishii H. Reliability of a flushing questionnaire and the ethanol patch test in screening for inactive aldehyde dehydrogenase-2 and alcohol-related cancer risk. Cancer Epidemiol Biomarkers Prev 1997;6:1105-7.

17. Craig CL, Marshall AL, Sjostrom M, Bauman AE, Booth ML, Ainsworth $\mathrm{BE}$, et al. International physical activity questionnaire: 12-country reliability and validity. Med Sci Sports Exerc 2003;35:1381-95.

18. Wu SY, Leske MC. Associations with intraocular pressure in the Barbados Eye Study. Arch Ophthalmol 1997;115:1572-6.

19. Yoshida M, Ishikawa M, Kokaze A, Sekine Y, Matsunaga N, Uchida Y, et al. Association of life-style with intraocular pressure in middle-aged and older Japanese residents. Jpn J Ophthalmol 2003;47:191-8.

20. Epstein M. Alcohol's impact on kidney function. Alcohol Health Res 
World 1997;21:84-92.

21. Badrick E, Bobak M, Britton A, Kirschbaum C, Marmot M, Kumari M. The relationship between alcohol consumption and cortisol secretion in an aging cohort. J Clin Endocrinol Metab 2008;93:750-7.

22. Pexczon JD, Grant WM. Glaucoma, alcohol, and intraocular pressure. Arch Ophthalmol 1965;73:495-501.

23. Helderman JH, Vestal RE, Rowe JW, Tobin JD, Andres R, Robertson GL. The response of arginine vasopressin to intravenous ethanol and hypertonic saline in man: the impact of aging. J Gerontol 1978;33:3947.

24. Crabb DW, Matsumoto M, Chang D, You M. Overview of the role of alcohol dehydrogenase and aldehyde dehydrogenase and their variants in the genesis of alcohol-related pathology. Proc Nutr Soc 2004;63:4963.

25. Jung JG, Kim JS, Kim YS, Oh MK, Yoon SJ. Hypertension associated with alcohol consumption based on the facial flushing reaction to drinking. Alcohol Clin Exp Res 2014;38:1020-5.

26. Klein BE, Klein R, Knudtson MD. Intraocular pressure and systemic blood pressure: longitudinal perspective: the Beaver Dam Eye Study. Br J Ophthalmol 2005;89:284-7.

27. Crabb DW, Edenberg HJ, Bosron WF, Li TK. Genotypes for aldehyde dehydrogenase deficiency and alcohol sensitivity: the inactive ALDH2(2) allele is dominant. J Clin Invest 1989;83:314-6.

28. Nemesure B, Honkanen R, Hennis A, Wu SY, Leske MC; Barbados Eye Studies Group. Incident open-angle glaucoma and intraocular pressure. Ophthalmology 2007;114:1810-5.

29. Anderson DR; Normal Tension Glaucoma Study. Collaborative normal tension glaucoma study. Curr Opin Ophthalmol 2003;14:86-90.

30. Kim JS. Korean alcohol guideline. Korean J Fam Pract 2015;5(Suppl): 117-9. 